\title{
Correlation of Mastication and Masticatory Movements and Effect of Chewing Side Preference
}

\author{
Simone Guimarães FARIAS GOMES \\ William CUSTODIO \\ Juliana Silva MOURA JUFER \\ Altair Antoninha DEL BEL CURY \\ Renata Cunha Matheus RODRIGUES GARCIA
}

Department of Prosthodontics and Periodontology, Piracicaba Dental School, State University of Campinas, Piracicaba, SP, Brazil

\begin{abstract}
The aims of this study were to correlate masticatory performance with mandibular movements during mastication, and to evaluate masticatory performance and mandibular movements of subjects with different types of mastication. Seventy-eight healthy dentate subjects were selected and divided into 2 groups: bilateral and unilateral chewers. This classification was set by using kinesiography during mastication of an artificial material. Unilateral mastication was defined as the majority of the cycles took place at one specific side. The same tracings used to define type of mastication were used to evaluate mandibular movements by means of its parameters. Masticatory performance was analyzed by comminution of the artificial material and a sieving method. Statistical analysis was performed by Spearman's correlation method, and Mann-Whitney and Student's t-test, when appropriate, at 5\% significance level. No correlation was found between masticatory performance and parameters of mandibular movement during mastication. Bilateral chewers presented significantly better $(\mathrm{p}<0.05)$ masticatory performance than unilateral ones, however no differences in parameters of mandibular movement were found between groups. Within the limits of this study, it may be concluded that parameters of jaw movements during mastication are not related to masticatory performance, and that the presence of a preferred chewing side worsens mastication.
\end{abstract}

Key Words: mastication, mandible, movement, side preference.

\section{INTRODUCTION}

The physiology and biophysics of the natural mastication of human beings play an important role to understand the development of the stomatognathic system (1). Chewing is a complex sensory-motor activity that involves manipulation and crushing of the food, as well as a pattern of rhythmic movements (2), under the control of a central pattern generator located in the brain stem (3). It is known that the neuromuscular control plays an important role in mastication (2), therefore, characteristics of the movement of the mandible during comminution of the food have been associated with quality of mastication.

Velocities of the jaw in the opening and closing phases of the chewing cycle were positively, while occlusal level of chewing cycle was negatively correlated with chewing performance, during a 10 -s test of almond fragmentation (4). Furthermore, some other parameters of mandibular movement, such as vertical amplitude, cycle duration and closing duration, were significant correlated with food mixing ability, being the former a positive and the other 2 parameters, negative correlations (5). The closing path was also associated to quality of mastication, being the closing angle negatively correlated with food mixing ability (5) and a convex closing path related to better masticatory function (6). Similar results were reported by Lepley et al. (7), who found a more horizontal path of cycle closure among better masticatory performers rather than in poorer chewers. Yamashita et al. (3) stated that the chewing cycle apparently increases its lateral component when increased masticatory efficiency is required, as during the mastication of large bolus or hard food. Moreover,

Correspondence: Profa. Dra. Renata Cunha Matheus Rodrigues Garcia, Departamento de Prótese e Periodontia, Faculdade de Odontologia de Piracicaba, UNICAMP, Avenida Limeira, 901, 13414-903 Piracicaba, SP, Brasil. Tel: +55-19-2106-5294. Fax: +55-19-2106-5211. e-mail: regarcia@ fop.unicamp.br 
Wilding and Lewin (8) reported that powerful predictors of chewing efficiency are smooth movements and constant velocity during mastication with wide and bilateral chewing cycles.

Mastication can be classified as bilateral, if it takes place bilaterally at the same time or on both sides alternately, and unilateral when it is consistently on one side (9). Some methods have already been proposed to study the preferred chewing side of individuals (10), including self-reports, this preference being present in $45.4 \%$ of the population (11).

It is not well established whether a preferred chewing side is regulated centrally or peripherally $(9,12)$. However, lateral asymmetry of bite force, asymmetry of occlusal contact area (9), unilateral joint clicking, unilateral pain in facial muscles or TMJs, asymmetric loss of posterior teeth, and use of acrylicbased removable partial denture are peripheral factors which has been reported to influence the habitual bilateral alternating chewing pattern, resembling the distribution of preferred chewing side (11). However, it is not known, whether the self-report method of a preferred chewing side used to report some of these associations (11) is reliable.

The question about the ideal chewing pattern remains unsolved (3). There is no consensus about either the characteristics of jaw movements or the association of bilateral chewing with better mastication overlapping unilateral chewing. This study aimed at correlating the parameters of mandibular movements and the presence or absence of a preferred chewing side with masticatory performance.

\section{MATERIAL AND METHODS}

Seventy-eight healthy dentate subjects ( 39 males and 39 females) with mean age of $23.5 \pm 4.1$ were selected among patients seeking for dental treatment, students and staff of Piracicaba Dental School, State University of Campinas, Brazil. To participate in the study, subjects should present good general and oral health, and full dentition (except for third molars). Individuals with severe malocclusion (e.g. open-bite, cross-bite) and history of signs and symptoms of temporomandibular disorders and/or parafunctional habits were excluded. The study was approved by the local Research Ethics Committee of Piracicaba Dental School (research protocol \#059/2004) and all subjects signed an informed consent form.

\section{Type of Mastication}

Akinesiograph (KNG) (K6-1; Evaluation System, Myotronics-Noromed, Inc., Kent, WA, USA) was used to record the mandibular track during mastication of a rubber base artificial material (Optosil; Heraeus Kulzer, Hanau, Hessen, Germany), by means of an electromagnetic field and a magnet bonded (Coe Pak; GC America Inc., Alsip, IL, USA) to the buccal face of the lower central incisors. The test was carried out with the participant sat in dental chair with the Frankfort Plane parallel to the ground. One portion of the artificial chewing material described previously was given to each participant, who chewed it during 15 chewing cycles, excluding the first stroke, as it usually shows different pattern. Each chewing stroke was broken into 3 phases: opening, closing and occlusal. A slice level was determined as vertical displacement of $0.7 \mathrm{~mm}$ below maximum intercuspation position. Tracing above the slice level and below maximum intercuspation was determined as occlusal phase. Each chewing cycle was identified from the starting time of an opening phase (the end of a previous occlusal phase) until the end of the next occlusal phase (5).

To determine whether the subjects presented bilateral alternating or unilateral (right or left) mastication, lateral deviation during the occlusal phase of each chewing cycle was analyzed. To present unilateral mastication or a chewing preferred side, the participant should perform $80 \%$ of the strokes coinciding on one side (10), i.e. 12 out of 15 chewing strokes. Subjects were then divided into 2 groups: unilateral and bilateral mastication. Additionally, before the tests had been performed, it was asked to the participants about the presence or absence of a preferred chewing side, and comparison between the kinesiographic recordings and the perception of the subjects was performed.

\section{Mandibular Path During Mastication}

The tracings used to classify the type of mastication were used to evaluate jaw movements during chewing. Each cycle and each cycle phase were identified as it has already been described on the latter topic. The following parameters were analyzed to evaluate mandibular movements: opening maximum velocity, closing maximum velocity, cycle duration, duration of opening phase, duration of closing phase, duration of occlusal phase, vertical excursion, posterior 
excursion, right and left excursions. The result of each parameter was given as the average of the second to the fifteenth cycle.

\section{Masticatory Performance}

Cubes of $5.6 \mathrm{~mm}$ of edge of a condensed silicone were obtained (Optosil, Heraeus Kulzer) using a metal matrix. After the setting of the material, the cubes were weighted for standardization and stored for $16 \mathrm{~h}$ at $60^{\circ} \mathrm{C}$ in an oven for its complete reticulation.

After, the cubes were cooled, disinfected at $2 \%$ glutaraldehyde solution for $30 \mathrm{~min}$, washed in tap water, dried with absorbent paper and grouped in portions of 17 cubes (13). Two portions were given to each subject, being the first to familiarization with the test conditions and the second to record data. Subjects were instructed to chew in their habitual way for 20 chewing strokes and expectorate the fragmented material in a paper filter, which was put in an oven for $25 \mathrm{~min}$ at $80^{\circ} \mathrm{C}$ for drying (14). The fragmented material was taken to the sieve system, composed by 10 sieves with apertures from 5.6 to $0.5 \mathrm{~mm}$, a bottom plate and a sieving machine (Bertel Indústria Metalúrgica Ltda., Caieiras, SP, Brazil). The particles contained in each sieve were weighted (Mark 2060; Bel Engineering s.r., Monza, Monza e Brianza, Italy) and masticatory performance was calculated using the Rosin-Rammler equation and given as the $\mathrm{x} 50$ value (mm) (13).

\section{Statistical Analysis}

Normality and degree of non-constant variance were checked for each response variable, using SigmaPlot statistics software (Version 11.0, Systat Software, Inc., Chicago, IL, USA). One-way ANOVA was used to analyze homogeneity of the sample, concerning weigh and high. Regarding to age, ANOVA on-Ranks was performed.

Correlation between masticatory performance and all mandibular movement parameters during mastication was assessed using Spearman rank correlation coefficient method. Evaluation of masticatory performance and mandibular movements during mastication between the 2 groups, unilateral and bilateral chewers, was performed as follows: Student's t-test for independent samples was used to analyze maximum closing velocity, number of cycles, cycle duration, duration of closing phase, duration of occlusal phase, maximum vertical amplitude, maximum posterior amplitude, maximum lateral amplitudes and maximum opening velocity, being the latter response variable transformed using $\log 10$. Masticatory performance and duration of opening phase data were analyzed using Mann-Whitney U-test. The significant level was set at $5 \%$.

\section{RESULTS}

No correlation $(p>0.05)$ was found between masticatory performance and any of the mandibular movement parameters.

Most participants showed no preferred chewing side, alternating bilateral strokes during mastication of artificial material. Frequency of bilateral, unilateral, preference for right or left side and coincidence of recorded KNG data and perception of subjects are shown in Table 1.

Bilateral chewers were able to comminute artificial chewing material to smaller particles than unilateral chewers. Mandibular movements during mastication were also evaluated, showing no statistical difference between groups for all parameters (Table 2).

\section{DISCUSSION}

Association of masticatory function and mandibular movements during mastication has been reported (4-8). The same relation was not found in the present study for any parameter of the mandibular movement during mastication investigated. The divergence of data may have occurred due to the different study designs and methodologies used in the present and cited studies to analyze jaw motion and masticatory

Table 1. Number and percentages for chewing preference and the coincidence of KNG data and subjects' perception.

\begin{tabular}{lc}
\hline Type of chewing & $\mathrm{N}(\%)$ \\
\hline Bilateral & $49(62.8)$ \\
Unilateral & $29(37.2)$ \\
Right & $16(20.5)$ \\
Left & $13(16.7)$ \\
KNG/Patient* & $37(47.4)$ \\
\hline
\end{tabular}

*Absolute and relative number of subjects whose perception of presence or absence of a chewing preferred side coincided with the kinesiographic data. 
function. Previous studies have used different materials, with distinct characteristics, number of particles, size and weight, for analysis, such as wine gum, almond, paraffin, wax cube, gummy jelly (4-8), while the present study used cubes made of a rubber based artificial material. It has been reported that chewing cycle alters its pattern according to the hardness or the size of bolus (3) and to the rheological properties of the food (15), suggesting the reason for such divergence of data.

Controversies also include studies concerning preferred chewing side, which has been determined by report of the subjects (11), visually by the operator (12) or with a kinesiograph (10), and following a variety of definitions, such as coincident strokes at one side between 55 and $80 \%$ of the total chewing cycles $(9,10)$, or the side the bolus is located at a certain time or counted strokes $(10,12)$. Regardless the technique or definition used, the right side seem to be preferred, ranging from 35 to $78.3 \%(9-12)$.

It is believed that bilateral chewing is much more common than it has been reported (16). Opposing to the findings of previous studies, most of the participants of the present study presented bilateral chewing $(62.8 \%)$ and $20.5 \%$, right side chewing preference. As it has already been mentioned, the present study used kinesiography to evaluate chewing side, which seems to be the most reliable technique, once it is able to detect unidentified cycles and very small lateral movements that may not be

Table 2. Masticatory performance and mandibular movement parameters between unilateral and bilateral chewers (Mean \pm s.d.).

\begin{tabular}{lccc}
\hline & Unilateral & Bilateral & p value \\
\hline Masticatory perf. (mm) & $5.56 \pm 2.11$ & $4.48 \pm 1.49$ & $0.01^{*}$ \\
Opening velocity $(\mathrm{mm} / \mathrm{s})$ & $118.41 \pm 32.07$ & $122.10 \pm 32.14$ & 0.59 \\
Closing velocity (mm/s) & $106.05 \pm 27.66$ & $109.30 \pm 22.53$ & 0.57 \\
Cycle duration (s) & $0.77 \pm 0.15$ & $0.80 \pm 0.16$ & 0.42 \\
Opening phase (s) & $0.23 \pm 0.05$ & $0.24 \pm 0.07$ & 0.28 \\
Closing phase (s) & $0.36 \pm 0.12$ & $0.37 \pm 0.11$ & 0.73 \\
Occlusal phase (s) & $0.18 \pm 0.09$ & $0.18 \pm 0.08$ & 0.99 \\
Vertical excursion (mm) & $16.54 \pm 3.28$ & $17.03 \pm 2.42$ & 0.46 \\
Posterior excursion (mm) & $5.19 \pm 2.11$ & $5.18 \pm 2.04$ & 0.99 \\
Right excursion (mm) & $2.44 \pm 1.23$ & $2.48 \pm 1.12$ & 0.91 \\
Left excursion (mm) & $3.55 \pm 1.74$ & $3.47 \pm 1.52$ & 0.82 \\
\hline
\end{tabular}

*Symbol indicates statistical significant difference. detected by visual methods (17). Cohesiveness of bolus should also be of significant importance during chewing, once foods or artificial materials of great cohesion, such as chewing gum $(10,12)$, is not dissociated and tend to be masticated unilaterally (17), differently from the rubber based artificial material (Optosil, Heraeus Kulzer). This may have contributed to the divergent outcomes between the present and the previous studies.

The chewing side preference perception coinciding with kinesiographic data occurred in $47.4 \%$ of the participants. If cohesiveness of food plays a role on chewing side preference, the difference between the perception of the subjects and the kinesiographic data might have occurred due to the difference of the material chewed during the test and the food each subject is used to eat. This is assumed because it has been stated that perceptual properties of texture lead to changes in intraoral food management (16). Based on these findings, it is suggested that self-report method should be used with caution.

It has been reported that bilateral chewing results in higher efficiency of mastication (8), which was confirmed by the present study that showed better masticatory performance in bilateral chewers. Minato et al. (18) showed that bilateral chewers presented more tongue acuity than unilateral chewers, and that this sensorial characteristic may play an important role on chewing efficiency. This association may have occurred because, during processing, food is kept on occlusal surfaces by movement of tongue and cheeks, ensuring that different parts of the food are comminuted in successive cycles. Additionally, it seems that food that requires more strokes to be processed is moved across the mouth (17) for a better chewing and manipulation. However, the pattern of this mediolateral motion has not been established (17). The frequent bilateral pattern found in the present study may also be a response for the great effort needed to crush the artificial chewing material used, once it is found to be of high deformation resistance (19).

Under the tested conditions, it can be concluded that masticatory performance is not correlated to a defined mandibular movement pattern, which did not differ between bilateral and unilateral chewers. However, alternating bilateral mastication promotes higher masticatory performance. 


\section{RESUMO}

Os objetivos deste estudo foram correlacionar a performance mastigatória com trajetória mandibular durante a mastigação, assim como avaliar performance mastigatória e trajetória mandibular de indivíduos com tipos diferentes de mastigação. Setenta e oito indivíduos saudáveis e dentados foram selecionados e divididos em 2 grupos: mastigação do tipo bilateral e unilateral. Esta classificação foi estabelecida utilizando-se um cinesiógrafo durante a mastigação de um material artificial. A mastigação foi definida como unilateral quando a maioria dos ciclos mastigatórios foi realizada em um lado específico. Os mesmos traçados obtidos para a classificação do tipo de mastigação foram usados para avaliar a trajetória mandibular durante esta função, por meio dos parâmetros do movimento. A performance mastigatória foi analisada pela trituração do material artificial mencionado e um sistema de peneiras. A análise estatística foi determinada pelo método de correlação de Spearman, e pelos testes de MannWhitney ou T-Student com nível de significância de 5\%. Não foi encontrada correlação entre performance mastigatória e os parâmetros da trajetória mandibular durante a mastigação. Indivíduos com mastigação bilateral apresentaram melhor performance mastigatória do que indivíduos com mastigação unilateral $(\mathrm{p}<0,05)$, contudo, os parâmetros da trajetória mandibular não foram diferentes entre os 2 tipos de mastigadores. Nos termos em que este estudo foi conduzido, pode-se concluir que os parâmetros do movimento mandibular durante a mastigação não estão relacionados com a performance mastigatória, que a presença de preferência de lado prejudica a mastigação.

\section{ACKNOWLEDGEMENTS}

We are very grateful to Dr. Jaime Aparecido Cury, Dra. Maria Beatriz Duarte Gavião and Thaís Marques Simek Vega Gonçalves for their assistance. This research was supported by National Council for Scientific and Technological Development - CNPq (Grant \#476385/2004-0 and 140204/2009-1).

\section{REFERENCES}

1. Escudeiro Santos C, Freitas O, Spadaro ACC, Mestriner-Junior W. Development of a colorimetric system for evaluation of the masticatory efficiency. Braz Dent J 2006;17:95-99.

2. Van der Bilt A, Engelen L, Pereira LJ, Van der Glas HW, Abbink JH. Oral physiology and mastication. Physiol Behav 2006;89:2227.

3. Yamashita S, Hatch JP, Rugh JD. Does chewing performance depend upon a specific masticatory pattern? J Oral Rehabil 1999;26:547-553.

4. Ow RKK, Carlsson GE, Karlsson S. Relationship of masticatory mandibular movements to masticatory performance of dentate adults: a method study. J Oral Rehabil 1998;25:821-829.

5. Yoshida E, Fueki K, Igarashi Y. Association between food mixing ability and mandibular movements during chewing of a wax cube. J Oral Rehabil 2007;34:791-799.

6. Kobayashi Y, Shiga H, Yokoyama M, Arakawa I, Nakajima K. Differences in masticatory function of subjects with different closing path. J Prosthodont Res 2009;53:142-145.

7. Lepley C, Throckmorton G, Parker S, Buschang PH. Masticatory performance and chewing cycle kinematics - are they related? Angle Orthod 2010;80:295-301.

8. Wilding RJ, Lewin A. The determination of optimal human jaw movements based on their association with chewing performance. Arch Oral Biol 1994;39:333-343.

9. Martinez-Gomis J, Lujan-Climent M, Palau S, Bizar J, Salsench $\mathrm{J}$, Peraire M. Relationship between chewing side preference and handedness and lateral asymmetry of peripheral factors. Arch Oral Biol 2009;54:101-107.

10. Varela JMF, Castro NB, Biedma BM, da Silva Domínguez JL, Quintanilla JS, Muñoz FM, et al.. A comparison of the methods used to determine chewing preference. J Oral Rehabil 2003;30:990-994.

11. Diernberger S, Bernhardt O, Schwahn C, Kordass B. Self-reported chewing side preference and its associations with occlusal, temporomandibular and prosthodontic factors: results from the population-based Study of Health in Pomerania (SHIP-0). J Oral Rehabil 2008;35:613-620.

12. Nissan J, Gross MD, Shifman A, Tzadok L, Assif D. Chewing side preference as a type of hemispheric laterality. J Oral Rehabil 2004;31:412-416.

13. de Matos LF, Pereira SM, Kaminagakura E, Marques LS, Pereira $\mathrm{CV}$, van der Bilt $\mathrm{A}$, et al.. Relationships of beta-blockers and anxiolytics intake and salivary secretion, masticatory performance and taste perception. Arch Oral Biol 2010;55:164-169.

14. Omar SM, McEwen JD, Ogston SA. A test for occlusal function. Brit J Orthod 1987; 14:85-90.

15. Foster KD, Woda A, Peyron MA. Effect of texture of plastic and elastic model foods on the parameters of mastication. J Neurophysiol 2006;95:3469-3479.

16. Mioche L, Hiiemae KM, Palmer JB. A postero-anterior videofluorographic study of the intra-oral management of food in man. Arch Oral Biol 2002;47:267-280.

17. Paphangkorakit J, Thothongkam N, Supanont N. Chewing-side determination of three food textures. J Oral Rehabil 2006;33:2-7.

18. Minato A, Ono T, Miyamoto JJ, Honda E, Kurabayashi T, Moriyama K. Preferred chewing side-dependent two-point discrimination and cortical activation pattern of tactile tongue sensation. Behav Brain Res 2009;203:118-126.

19. Olthoff LW, Van der Bilt A, De Boer A, Bosman F. Comparison of force-deformation characteristics of artificial and several natural foods for chewing experiments. J Texture Stud 1986;17:275-289.

Accepted August 3, 2010 